\title{
ARTICLE \\ Revisiting the shortage of seafarer officers: a new approach to analysing statistical data
}

\section{Lijun Tang $^{1}$ (iD . Syamantak Bhattacharya ${ }^{2}$}

Received: 6 July 2021 / Accepted: 6 October 2021 / Published online: 28 October 2021

(c) World Maritime University 2021

\begin{abstract}
The BIMCO/ICS maritime manpower surveys have been consistently indicating a shortage of seafarer officers. However, due to data deficiencies, this shortage thesis has been challenged. This paper develops a new methodological approach to estimating the supply and demand for officers. It analyses and triangulates different sets of data released by national maritime authorities. The analysis shows that in fact there is an oversupply of officers. Nevertheless, the supply of chief officers and second engineers may be tight. This insight can help maritime authorities and the industry make informed decisions regarding maritime human resource development. Furthermore, the new approach provides a useful tool for national maritime authorities to work out and monitor the supply and demand balance of their seafarer officers.
\end{abstract}

Keywords Seafarer labour market · Manpower report $\cdot$ Seafarer shortage $\cdot$ Supply and demand for seafarers

\section{Introduction}

The international shipping industry is pivotal to the global economy by carrying about $80 \%$ of world trade by volume (UNCTAD 2019). The smooth running of the industry depends on a workforce of more than 1.6 million seafarers worldwide (BIMCO/ICS 2015). In modern organisations, people are seen as the most valuable asset. This is certainly the case in shipping, and as such, crewing management is regarded to be crucial in their business operations by shipping companies

Lijun Tang

Lijun.tang@plymouth.ac.uk

Syamantak Bhattacharya

syamantak.bhattacharya@solent.ac.uk

1 Plymouth Business School, University of Plymouth, Cookworthy Building, Drake Circus, Plymouth PL4 8AA, UK

2 Solent University, Southampton E Park Terrace, Southampton SO14 0YN, UK 
(Deloitte 2011). In this context, it is important to develop a good understanding of the seafarer labour market and a comprehensive picture of the seafarer population. To this end, the Baltic and International Maritime Council (BIMCO) together with the International Chamber of Shipping (ICS) ${ }^{1}$ have been conducting surveys of seafarer labour supply and demand on a global scale regularly since 1990. These surveys are influential and have been used as the starting point for future human resource development initiatives in the industry.

Maritime shipping is a global industry with mobile workplaces (the ships), and ship owners and managers in most cases are able to employ seafarers from any labour supply country. This gives rise to a global seafarer labour market (ILO 2001). Without any doubt, it is challenging to survey such a mobile, fluid and diverse workforce on a global scale. While the BIMCO/ICS surveys achieve unparalleled breadth covering the worldwide supply and demand, the reliability and accuracy of their data are often questioned (Leggate 2004; Li and Wonham 1999; Manoj 2018). One source of inaccuracy is related to the problem that the number of seafarers is notoriously difficult to estimate. The maritime authorities may have data on the total number of people who hold a valid seafarer certificate at any given time. However, they have little idea of how many of them are still active seafarers (i.e. those who are working, or intending to find employment, at sea) or how many have left the profession or retired. Given this challenge, it is highly improbable for the BIMCO/ICS surveyors to have an accurate estimation of the supply of seafarers as they rely on the figures provided by national maritime authorities.

Since its inception, the key finding of BIMCO/ICS surveys has been that there is a current, as well as a projected future, shortage of seafarer officers. However, due to the data inadequacies, research has shown that these surveys tended to significantly underestimate the supply (Leggate 2004; Li and Wonham 1999). Thus, though influential, the shortage thesis remains debatable.

In this context, this paper has two objectives. First, it develops a new approach to estimating the supply and demand for seafarer officers by analysing and triangulating different sets of data released by national maritime authorities. This approach does not rely on problematic data about the number of active seafarers, but makes use of robust statistical data on seafarer deployment, certification and training that are collected and released by national maritime administrations. As such, it is able to generate more accurate, more in-depth and more nuanced findings. To demonstrate this approach, this paper conducts two case studies examining the data released by Filipino and Indian maritime authorities respectively. The findings from the case studies help achieve the second objective of the paper, which is to revisit the shortage thesis and draw out practical and policy implications. Before conducting the case studies, the next section reviews the previous approaches to studying the seafarer labour market.

\footnotetext{
1 The initial surveys were conducted by the Baltic and International Maritime Council (BIMCO) and the International Shipping Federation (ISF). In 2011, the ISF merged into the ICS. For convenience, all the manpower surveys/reports were referred to as BIMCO/ICS surveys/reports in this paper.
} 


\section{Researching the seafarer labour market}

There have been two approaches to studying the seafarer labour market (Glen 2008; Tang and Zhang 2021). One relies on crew lists collected from a sample of ports during a period of time (Ellis and Sampson 2008; US Maritime Administration, 2006; Wu and Winchester,2005). A crew list contains the name, type and flag of the ship, and age, rank, and nationality of the crew who are working on the ship at the point of data collection. By collating the information obtained from crew lists, researchers are able to construct the profile of the seafaring workforce in the sample and then extrapolate the findings to the overall workforce working in the global fleet. With an estimated backup ratio to take into account those on leave, it is possible to figure out the total demand for seafarers and their compositions. Regarding supply, however, crew lists offer no insight. Furthermore, due to data security issues, crew lists are difficult to collect and no new or updated survey has been conducted since the early 2000 s.

Another approach estimates both supply and demand. Regarding the former, it collects the estimated numbers of seafarers in labour supply countries from the national maritime authorities, as done by the BIMCO/ICS manpower reports and updates. This approach has two problems (Leggate 2004; Li and Wonham 1999). First, some countries do not have established systems to record seafarer information. Second, many countries may have a good record of issued seafarer certificates, but the number of certificates is not the same as that of active seafarers. Certificates are generally valid for 5 years, during which period attrition naturally occurs and many seafarers would leave the profession. No national maritime authorities have made the effort to collect data on seafarer attrition. For example, while the European Maritime Safety Agency (EMSA) has good statistical data of seafarers with valid certificates issued by the European Union (EU) member States, they acknowledge that they do not have information on the number of active seafarers in the EU (EMSA 2020). It remains a problem to work out the number of active seafarers. For the reasons mentioned above, surveys conducted by different teams can produce results with staggering discrepancies. Leggate (2004) showed the difference between the ILO 2001 study and the BIMCO/ICS 2000 survey. While both studies assimilated data from the same sources, the former reported a total number of 997,803 seafarers and BIMCO/ICS did 455,583 from the same 35 countries.

Since 2008, the Drewry Manning Report has been published annually by Drewry Shipping Consultants in conjunction with Precious Associates Limited. These reports cover topics including global seafarer supply and demand, seafarer wages and employment terms, and other manning issues. Similar to the BIMCO/ ICS surveys, the Drewry reports have consistently pointed to a shortage of officers. Nevertheless, regarding the supply of officers, there are also big discrepancies between Drewry and BIMCO/ICS data. For example, Drewry (2017) indicated that the global supply of officers in 2015 was 610,000 , while BIMCO/ICS (2015) estimated it to be 774,000; Drewry reported that China supplied 53,500 officers in 2015, but BIMCO/ICS suggested that about 101,600 Chinese officers 
Table 1 Deployment of Filipino seafarers by categories 2012-2017

\begin{tabular}{lllllll}
\hline & 2012 & 2013 & 2014 & 2015 & 2016 & 2017 \\
\hline Officer & 84,836 & 86,636 & 93,686 & 93,992 & 100,605 & 100,185 \\
Rating & 136,505 & 139,211 & 154,963 & 148,283 & 159,858 & 163,903 \\
Non-marine & 129,822 & 132,396 & 151,402 & 161,480 & 179,203 & 185,375 \\
Total & 351,163 & 358,243 & 400,051 & 403,755 & 439,666 & 449,463 \\
\hline
\end{tabular}

(Source: POEA Overseas Employment Statistics)

were supplied in the same year. Although the Drewry reports detailed the methodology adopted to estimate the global demand for seafarers, they did not explain the sources of information regarding seafarer supply. As such, it is not possible to evaluate the reliability and accuracy of their data. Nevertheless, whereas Drewry (2017) reported the Philippines and India supplied 75,000 and 44,500 officers respectively in 2015 , the data released by the respective national authorities showed that 93,992 Filipino and 50,354 Indian officers were actually deployed in the same year (for more details, see Tables 1 and 5). This indicates that the Drewry reports may underestimate the supply.

The BIMCO/ICS surveys calculate demand based on the number of ships, estimated manning levels and backup ratios. Drewry adopts the same methodology, but its approach to backup rations is more nuanced. For example, it divides seafarer officers into four regional groups, Northwest European, East European, Far East and Indian Subcontinent; officers from northwest Europe are estimated to have higher backup rations (1.90:1) than their colleagues from other parts of the world (1.50:1), which reflects that the former enjoy better employment terms and conditions than the latter (Drewry 2017; see also Ellis et al. 2012). Both the BIMCO/ICS and Drewry surveys are conducted regularly and both have been consistently reporting a shortage of seafarer officers. For example, according to the 2015 BIMCO/ICS Manpower Report (BIMCO/ICS 2015), the global supply of seafarer officers in 2015 was approximately 774,000 , but the global demand for officers in the same year stood at 790,500 , indicating a shortage of 16,500 officers.

The BIMCO/ICS reports have been influential and the officer shortage thesis is widely discussed in the industry (Leong 2012; Sulpice 2011). In a follow-up study, Leong (2012) interviewed some ship and crewing managers to find out their experience of shortage in practice. The findings suggested that the shortage was more at the senior officer level. More often than not, however, the officer shortage is taken for granted and seen as a problem to be addressed. To mitigate the shortage, various measures related to recruitment and retention have been suggested (e.g. Bao et al. 2021; Bhattacharya 2015; Caesar et al. 2020; De Silva et al. 2011; Lu et al. 2018). To take advantage of the growing demand for seafarers, the Philippines, China, India and many other developing countries have been expanding their training capacities and adopting policies to recruit and train more officer trainees (Tang et al. 2016; Tang and Zhang 2021). As a response to the decline in the number of UK seafarers, the UK government has also implemented policies to support 
cadet training since the 1990s in the hope of increasing British seafarer numbers (Gekara 2010).

The BIMCO/ICS reports, however, are based on problematic data as discussed above. Policy interventions and recommendations need to be built on and guided by robust data and analysis. To this end, this paper introduces a different approach to gauging the supply and demand for officers. Rather than estimate supply and demand directly, it examines whether newly certified officers could be fully deployed or not. If not, this indicates an oversupply. Both Filipino and Indian maritime authorities release annual statistical data on seafarer deployment, STCW CoC issuance and cadet training. These sets of data are more robust than the estimated supply and demand figures, and as such, the findings would be more reliable. Even though this paper only covers two seafarer supplying countries, the findings may apply elsewhere since the seafarer labour market is fluid and global.

It is worth mentioning that the sets of data released by both Filipino and Indian authorities are only up to 2017. As the data for the recent few years are not available in the public domain, this paper only examines the supply/demand situations of Filipino and Indian officers up to 2017. It does not assess the current situation affected by the COVID-19 pandemic. Though BIMCO/ICS has recently published its 2021 Seafarer Workforce Report, the reference point in this paper is the BIMCO/ ICS 2015 report. Nevertheless, since all BIMCO/ICS surveys adopt the same methodology, they share the same methodology-related shortcomings as discussed in this paper.

\section{The case of Filipino seafarers}

In the Philippines, the Philippine Overseas Employment Administration (POEA) processes overseas employment of Filipino seafarers and issues an overseas employment certificate to each seafarer deployed overseas. As this is a prerequisite, the information collated by POEA should represent an accurate picture of the demand for Filipino seafarers in the market. Table 1 shows the numbers of Filipino seafarers deployed internationally between 2010 and 2017 as collated and released by POEA. ${ }^{2}$ This data clearly indicates that the Manpower Report significantly underestimated the supply of Filipino officers. While the Manpower Report (BIMCO/ICS 2015) estimated a supply of 72,500 Filipino officers in 2015, in reality, a total number of 93,992 Filipino officers were deployed in that year (21,492 more than the BIMCO/ ICS estimation). Were these extra Filipino 21,492 officers alone taken into account, the shortage of 16,500 officers as indicated in the Manpower Report would change to an oversupply of 4992.

It is worth noting that Table 1 shows deployment figures, and that deployment is not the same as supply. There are three scenarios. First, when the supply and demand are in balance, the number of deployments equals that of supply as well as

\footnotetext{
2 'Non-marine' includes those working on cruise ships providing catering services as waiters and waitresses. This paper focuses on officers only.
} 
Table 2 Number of Filipino marine officer $\mathrm{CoC}$ examination passers 2015-2017

\begin{tabular}{lll}
\hline & OIC-NW & OIC-EW \\
\hline 2015 & 5639 & 3144 \\
2016 & 8202 & 5097 \\
2017 & 7405 & 4409 \\
Total & 21,246 & 12,650 \\
\hline
\end{tabular}

(Source: MARINA statistics)

that of demand. Second, when there is a shortage in supply, all the supply would be deployed; and in this case, the supply would be the same as the deployment. In the third scenario when there is an oversupply, however, the number of deployments reflects the actual demand; as the demand is limited, the total supply would be more than the number of deployment.

To find out which scenario Filipino officers are in, it is necessary to bring in the second set of data, Filipino marine officer Certificate of Competency (CoC) examination statistics released by the Maritime Industry Authority (MARINA) of the Philippines. Table 2 shows that from 2015 to 2017, a total number of 21,246 Filipino seafarers acquired an Officer in Charge of Navigational Watch (OICNW) CoC and another 12,650 obtained an Officer in Charge of an Engineering Watch (OIC-EW) CoC. These were new blood into the supply of officers. It is worth mentioning that officers with an OIC-NW CoC or an OIC-EW CoC can only serve as junior officers. To be able to serve as a senior officer, they need to take further training and exams to acquire a higher level CoC. As POEA's deployment statistics lump officers together without detailed information on each rank, the deployed officers can be seen as one group regardless of their ranks. Every year, there are some officers exiting the group and new officers joining in. Assuming the supply and demand for officers in Year $y$ are in balance (i.e. all the supplies are deployed), in Year $y+1$ attrition inevitably occurs as some officers exit this group. At the same time, the deployment in Year $y+1$ may also expand due to an increase in demand. As such, the newly certified officers would be deployed to (1) replace those who exited the group and (2) fill the officer positions newly created. This is not the say that a newly certified junior officer can replace a senior officer or fill a newly created senior officer position. It simply means that when a senior officer position is created, one of the officers in the next rank who is suitably qualified would be promoted to fill it, which leaves a position to be filled by an officer in the next rank. This in the end opens a position for a newly certified officer. Therefore, in this process, while those who exit the group are in various ranks, the newly joined ones are the newly certified. Based on the above discussion, the equation below can be applied to estimate how many of the newly certified are deployed in Year $y+1$ :

Assuming the supply and demand for officers in Year $y$ are in balance:

$$
\mathrm{NDP}_{y+1}=A^{*} \mathrm{DP}_{y}+\left(\mathrm{DP}_{y+1}-\mathrm{DP}_{y}\right)
$$


Table 3 Supply and deployment of newly certified Filipino officers 2015-2017

\begin{tabular}{llll}
\hline & $\begin{array}{l}\text { No. of newly certi- } \\
\text { fied officers }\end{array}$ & $\begin{array}{l}\text { No. of newly } \\
\text { deployed officers }\end{array}$ & Oversupply \\
\hline 2015 & 8783 & 2648 & 6135 \\
2016 & 13,299 & 8963 & 4336 \\
2017 & 11,814 & 2095 & 9719 \\
Total & 33,896 & 13,706 & 20,190 \\
\hline
\end{tabular}

where $\mathrm{NDP}_{y+1}$ is the number of newly deployed officers in Year $y+1 ; A$ indicates the attrition rate; $\mathrm{DP}_{y}$ represents the number of deployed officers in Year $y$ and $\mathrm{DP}_{y+1}$ represents the number of deployed officers in Year $y+1$.

It is worth noting that in some cases, the value of $\mathrm{DP}_{y+1}$ may be smaller than that of $\mathrm{DP}_{y}$, indicating that the deployment decreased in Year $y+1$ as compared with that in Year $y$. Theoretically, an extreme case is that $\mathrm{DP}_{y+1}$ is zero. This gives $\mathrm{NDP}_{y+1}$ a negative value. It means that in this case, except for those who have left the profession, the remaining officers deployed in Year $y$ become un-deployed in Year $y+1$.

The only unknown factor on the right side of the equation is the attrition rate $A$. Based on the questionnaire survey data from shipping companies, BIMCO/ICS (2015) reported that the attrition rate of employed seafarer officers in 2015 was estimated to be around 2.3 to $2.4 \%$. On this basis, the annual attrition rate $A$ is set at $2.5 \%$ in this paper. Calculated with the figures in Table 1, the numbers of newly deployed officers in 2015, 2016 and 2017 would be 2648, 8963 and 2095 respectively (see Table 3). Thus, in the 3 years, the total demand for new officers was 13,706 , but the number of the newly certified amounted to 33,896. This indicates an oversupply of 20,190 officers (about $60 \%$ of the newly certified) in the 3 years from 2015 to 2017, based on the assumption that the demand and supply were in balance in 2014. When a large proportion of the newly certified officers were not deployed as officers between 2015 and 2017, however, it was likely to be the case that many of the newly certified Filipino officers were in a similar situation before and in 2014. Those surplus seafarers were likely to be employed as ratings, though holding CoCs.

The figures of oversupply as shown in Table 3 are staggering. Though not officially released by the POEA, The Manila Times reported that Filipino seafarer deployment in 2018 hit 337,502, 111,961 lower as compared with the figure of 449,463 in 2017 (Ayeng 2019). Even though a separate figure of officer deployment was not provided, it is reasonable to assume that tens and thousands of Filipino officers lost employment in 2018. This further added to the problem of oversupply.

The oversupply calculated above is only about Filipino officers. However, the seafarer labour market is a global one into which Filipino seafarers have long been well integrated. If there were a shortage elsewhere in the world, it would be unlikely that ship managers fail to notice the abundant supply of Filipino officers. Therefore, the demand/supply situation of Filipino officers is likely to reflect that of the officers globally.

When BIMCO/ICS reported a shortage of officers, it was perceived that recruitment was a problem. Regarding Filipino seafarers, however, this was not an issue. 
Table 4 Number of enrolled MET students in the Philippines 2011-2015

\begin{tabular}{llllll}
\hline & $2011-2012$ & $2012-2013$ & $2013-2014$ & $2014-2015$ & $2015-2016$ \\
\hline BSMT & 62,293 & 81,101 & 79,435 & 83,148 & 128,420 \\
BSMarE & 44,898 & 58,537 & 104,669 & 61,128 & 96,103 \\
Total & 107,191 & 139,638 & 184,104 & 144,276 & 224,523 \\
\hline
\end{tabular}

(Source: MARINA statistics)

Table 5 Deployment of Indian officers 2010-2017

\begin{tabular}{lllllllll}
\hline & 2010 & 2011 & 2012 & 2013 & 2014 & 2015 & 2016 & 2017 \\
\hline Capt & 4204 & 4576 & 5221 & 5493 & 5728 & 6102 & 6601 & 6742 \\
C Off & 3781 & 4054 & 4530 & 4844 & 5218 & 5522 & 6203 & 6361 \\
2nd Off & 3805 & 4222 & 4753 & 5280 & 5767 & 6155 & 6770 & 7006 \\
3rd Off & 3441 & 4006 & 4491 & 4906 & 5409 & 5795 & 6569 & 6824 \\
C. Eng & 3593 & 4207 & 4679 & 4989 & 5146 & 5391 & 5961 & 6218 \\
2nd Eng & 3784 & 4153 & 4695 & 5059 & 5406 & 5667 & 6187 & 6424 \\
3rd Eng & 3475 & 3787 & 4266 & 4568 & 4863 & 5176 & 5881 & 6098 \\
4th Eng & 2845 & 3239 & 3649 & 4071 & 4428 & 4787 & 5534 & 5766 \\
E. Off & 4156 & 4535 & 4964 & 5083 & 5694 & 5759 & 6518 & 6619 \\
Total & 33,084 & 36,779 & 41,248 & 44,293 & 47,659 & 50,354 & 56,224 & 58,058 \\
\hline
\end{tabular}

Table 4 shows that a large number of students enrolled in Bachelor of Science in Marine Transportation (BSMT) and Bachelor of Science in Marine Engineering (BSMarT) programmes for deck and engine cadet training in the Philippines. On average, the number of enrolled students each year during the 2011-2015 period was about 160,000 . As the degree courses take 4 years to complete, the newly enrolled per year would be more than 40,000. However, it was reported that less than $20 \%$ of them were able to complete their training (Mendoza and Valenzuela 2017). One major reason for this was that they could not secure a training berth for shipboard training. ${ }^{3}$ Thus, at the training stage, a severe lack of demand has prematurely terminated the aspirations of a large number of students to become seafarer officers.

\section{The case of Indian seafarers}

Directorate General of Shipping (DG Shipping) is the maritime authority in India. It releases two sets of statistical data on Indian seafarers: one is deployment data (Table 5) and the other CoC exam data (Tables 6 and 7). Both are broken down by rank and year. This enables an analysis of the supply situation of each rank.

\footnotetext{
3 To become a certified officer, an officer cadet should acquire competencies through a combination of college-based education and practical training onboard ships before taking the CoC exams.
} 
Table 6 New CoC issued to deck officers by DG Shipping 2011-2017

\begin{tabular}{llllllll}
\hline & 2011 & 2012 & 2013 & 2014 & 2015 & 2016 & 2017 \\
\hline Capt & 592 & 449 & 465 & 402 & 484 & 760 & 731 \\
Chief Off & 784 & 804 & 965 & 793 & 1013 & 1069 & 1038 \\
Junior Off & 2254 & 2000 & 2021 & 1965 & 2161 & 2333 & 2432 \\
\hline
\end{tabular}

Table 7 New CoC issued to engine officers by DG Shipping 2015-2017

\begin{tabular}{llll}
\hline & 2015 & 2016 & 2017 \\
\hline Chief Eng & 562 & 625 & 592 \\
2nd Eng & 838 & 998 & 1176 \\
Junior Eng & 2394 & 2628 & 2832 \\
\hline
\end{tabular}

An analysis is first conducted on the number of junior (2nd and 3rd) deck officers. Every year, there are cadets passing the exams and obtaining an OIC-NW $\mathrm{CoC}$ and become eligible to enter this group of officers. Again, assuming that in Year $y$, the deployment and supply of junior officers are in perfect balance, newly certified junior officers in Year $y+l$ would be deployed in this year for three purposes. First, some 2nd officers would be promoted to chief officers in Year $y+1$ and leave the junior officer group. This creates 2 nd officer positions to be filled by existing 3rd officers whose positions in turn would be filled by newly certified junior officers. Second, a number of junior officers deployed in Year $y$ would leave the profession in Year $y+1$. This attrition again leaves vacancies to be filled by newly certified junior officers. Third, there are more junior officers deployed in Year $y+1$ than in Year $y$, which creates new positions to be filled by newly certified junior officers. Therefore, the number of newly certified officers deployed as junior officers in Year $y+l$ can be calculated with the following equation:

Assuming the supply and demand for officers in Year $y$ are in balance:

$$
\mathrm{NDP}_{y+1}=P_{y+1}+A^{*} \mathrm{DP}_{y}+\left(\mathrm{DP}_{y+1}-\mathrm{DP}_{y}\right)
$$

where $\mathrm{NDP}_{y+1}$ is the number of newly deployed officers in Year $y+1 ; P_{y+1}$ denotes the number of officers promoted (to chief officers) in Year $y+1$; $A$ indicates the attrition rate; $\mathrm{DP}_{y+1}$ represents the number of deployed officers in Year $y+1$ and $\mathrm{DP}_{y}$ represents the number of deployed officers in Year $y$.

To calculate the number of newly deployed junior officers with the equation above, the numbers of deployed junior officers in Year $y+1$ and Year $y$ are available in Table 5, and the attrition rate is again set at $2.5 \%$. The remaining task is to estimate the number of officers promoted to chief officers. It is true that the majority of 2 nd officers who acquired a Chief Officer CoC in Year $y+1$ may need to wait for a few years to be promoted in practice. However, many 2 nd officers who obtained a Chief Officer $\mathrm{CoC}$ in previous years would get promoted in Year $y+1$. As such, it is reasonable to assume that the number of promoted officers can be approximated by that of officers who obtain a Chief Officer $\mathrm{CoC}$ in the 
Table 8 Supply and deployment of newly certified deck officers 2011-2017
Certified

2011-2017
Newly deployed

2011-2017
Oversup-

ply/short-

age

\begin{tabular}{llll}
\hline Junior Off & 15,166 & 14,834 & 332 \\
Chief Off & 6466 & 7317 & -851 \\
Capt & 3833 & 3486 & 178 \\
Total & 25,465 & 25,637 & -172 \\
\hline
\end{tabular}

Table 9 Supply and deployment of newly certified engineering officers 2015-2017

\begin{tabular}{llll}
\hline & $\begin{array}{l}\text { Certified } \\
2015-2017\end{array}$ & $\begin{array}{l}\text { Newly deployed } \\
\text { 2015-2017 }\end{array}$ & $\begin{array}{l}\text { Oversup- } \\
\text { ply/short- } \\
\text { age }\end{array}$ \\
\hline Junior Eng & 7854 & 6459 & 1395 \\
2nd Eng & 3012 & 3288 & -276 \\
Chief Eng & 1779 & 1541 & 238 \\
Total & 12,645 & 11,288 & 1357 \\
\hline
\end{tabular}

year. This is particularly the case when the calculation covers a few years. Therefore, the number of newly deployed junior officers in a particular year can be calculated with the data in Tables 5 and 6.

The same principle and method are then applied to other ranks. In the cases of captains and chief engineers, they are already on the top of the hierarchy with no room for promotion in the seafaring career, and as such, the number of promotions is zero. They exit the professional group through attrition only.

Table 8 shows the results for deck officers. The third column indicates the total number of newly deployed officers by rank between 2011 and 2017. The second column shows the total number of newly certified officers (who are new supplies) by rank in the same period. If the number of the newly certified is bigger than that of the newly deployed, it indicates an oversupply; otherwise, it indicates a shortage. In practice, a shortage would not happen because a country cannot deploy more officers than it can supply. Therefore, there is a discrepancy between reality and the results in Table 8 which are based on theoretical calculations. This discrepancy can be explained by the practice that $\mathrm{CoC}$ statistics in Table 6 only included those issued by DG Shipping. However, there were also a few hundred Indian seafarers taking training abroad and obtaining CoCs issued by British, Australian or Singapore maritime authorities. As they were Indian seafarers, they were included in the deployment data in Table 5. While there is no official data on this group of Indian seafarers, it is reasonable to assume that they make up the discrepancy. Table 9 shows the results for engineers between 2015 and 2017. Overall there was an oversupply of 1357 by the end of 2017.

The results show the supply/deployment balance of Indian seafarers. If the results about chief officers and 2nd engineers could be seen to be in perfect balance (i.e. all the supplies are deployed), then there was a modest oversupply in junior ranks. Nevertheless, compared with their Filipino counterparts, Indian junior officers were 
Table 10 Number of cadets deployed at sea and number of CoC issued

\begin{tabular}{lllllllll}
\hline & 2010 & 2011 & 2012 & 2013 & 2014 & 2015 & 2016 & 2017 \\
\hline Deck cadets deployed & 3658 & 4182 & 4653 & 5312 & 5464 & 5214 & 5440 & 5469 \\
Junior officer CoC & - & 2254 & 2000 & 2021 & 1965 & 2161 & 2333 & 2432 \\
Engine cadets deployed & 2268 & 2588 & 2815 & 3172 & 3297 & 3612 & 4048 & 4120 \\
Junior engineer CoC & - & - & - & - & - & 2394 & 2628 & 2832 \\
\hline
\end{tabular}

in a much better position and it would not be difficult for them to secure officer positions. If the demand in the international market increases, there would be a shortage of chief officers and 2 nd engineers. The data seems to indicate that when there is no shortage, ship managers prefer Indian junior officers to Filipino ones. This may be because cadet training provided by some colleges in the Philippines does not meet the expected standards (Sampson and Bloor 2007), which has consistently been a concern of the European maritime authorities (Hand 2018).

Regarding cadet training, however, there was a big problem in India as well. Table 10 shows that more than half of Indian deck cadets could not complete their training successfully. Engine cadets were in a better position and more than half completed training in the period of 2015-2017 (see Table 10). According to a report, in 2018, more than 5000 cadets who had completed shore-based training were not able to complete the mandatory shipboard training due to a lack of training berths (Manoj 2018).

\section{Concluding discussion}

This paper makes two contributions. First, it introduces a new method to examine the supply and demand balance of seafarer officers. Instead of estimating supply and demand directly, this method examines whether or not newly certified officers could be fully deployed. As the deployment and certification data collected and released by national maritime authorities are more robust, the findings are more reliable. This new approach provides a useful tool for national maritime authorities to work out and monitor the supply and demand balance of their seafarer officers, and to take policy initiatives and interventions accordingly in order to develop maritime human resources.

The second contribution of this paper is that it sheds new light on the officer shortage thesis. The analyses of Filipino seafarers' certification, deployment and training statistical data indicate that there was no shortage of operational level (or junior) officers. Instead, there was a problem of oversupply - tens and thousands of certified Filipino officers could not find employment as officers. At the same time, about 10,000 Filipino seafarers obtained their first $\mathrm{CoC}$ each year, but more than half of them would find it difficult to secure an officer position. Furthermore, more than 40,000 new cadets were recruited each year and only a small proportion of them could complete the training. The Indian case reveals that while there 
was also a moderate oversupply, Indian junior officers were in a better position and would not find it difficult to secure deployment. Similarly, a large proportion of Indian cadets could not complete their training either.

Was there a shortage of officers as indicated by the BIMCO/ICS 2015 report? The answer is more nuanced than a simple yes or no. Taken together, these two case studies indicate that overall there was an oversupply of officers rather than a shortage as suggested by the BIMCO/ICS report, at least before the COVID19 pandemic. Nevertheless, a more detailed rank level analysis of Indian officers reveals that despite the overall oversupply, the supply of chief officers and second engineers was tight, which might indicate a shortage in these two ranks. This corroborates the findings of Leong's (2012) qualitative study in which some ship and crewing managers interviewed pointed out that the shortage was at the senior officer level.

This paper only covers two major seafarer labour supplying countries. However, the seafarer labour market is fluid and global, which means that if there is a shortage somewhere, ship managers there could easily recruit from other places where there is an abundant supply. Since both Filipino and Indian seafarers have long been integrated into the global labour market, the oversupply of junior officers and a tight supply of senior officers in these two countries are likely to reflect the global trend.

Thus, the officer shortage claim made in the BIMCO/ICS 2015 report is misleading. It has been seen by labour supplying countries as an opportunity to expand seafarer cadet recruitment and training capacities (Tang et al. 2016; Tang and Zhang 2021). However, resources are limited; and in the context of an oversupply of junior officers, focusing on quality would be much wiser and more effective than spreading investments and efforts thinly to strive for quantity. This is especially the case in countries where training quality is wanting. Improved quality makes officers more competent and competitive in the labour market. This is beneficial not only to the specific nation but also to the whole industry in terms of developing human resources. Furthermore, as there is a shortage of chief officers and second engineers, policy interventions and resources from labour supplying countries and the industry should focus more on growing human resources in these two ranks.

It is also necessary to acknowledge that the approach introduced in this paper has its own limitation. Not many countries collect and release seafarer deployment data. Therefore, there is not sufficient data to build up a comprehensive picture of the global labour market with this approach. Nevertheless, it can be used to complement other approaches. As a few major seafarer labour supplying countries provide detailed statistical data on seafarer deployment, certification and training, it is possible to triangulate these sets of data to work out the supply and demand situation at a national level. This information in turn can shed light on the global situation because the labour market is a global one. Therefore, the accuracy of future BIMCO/ICS manpower survey results can be improved by conducting a few complementary indepth case studies focusing on the major labour supplying countries in addition to the conventional and broad global survey. 


\section{Declarations}

Conflict of interest The authors declare no competing interests.

\section{References}

Ayeng R (2019) PH seafarer deployment cut by more than 100,000. The Manila Times. https://www. manilatimes.net/2019/03/30/news/top-stories/ph-seafarer-deployment-cut-by-more-than-100000/ 532671/. Accessed 30 June 2021

Bao J, Li Y, Zheng G, Zhang P (2021) Exploring into contributing factors to young seafarer turnover: empirical evidence from China. J Navig 1-17.

Bhattacharya Y (2015) Employee engagement as a predictor of seafarer retention: a study among Indian officers. Asian J Shipp Logist 31(2):295-318

BIMCO/ICS (2015) Manpower report-the global supply and demand for seafarers in 2015.

Caesar LD, Cahoon S, Fei J (2020) Understanding the complexity of retention among seafarers: a perspective of Australian employers. Aust J Marit Ocean Aff 12(1):16-41

De Silva R, Stanton P, Stanton J (2011) Determinants of Indian sub-continent officer-seafarer retention in the shipping industry. Marit Policy Manag 38(6):633-644

Deloitte (2011). Challenge to the industry-securing skilled crews in today's marketplace. https://www. mondaq.com/uk/marine-shipping/123404/challenge-to-the-industry--securing-skilled-crews-intodays-marketplace

Drewry. (2017). Manning annual report 2017. Drewry.

Ellis N, Sampson H. (2008) The global labour market for seafarers working aboard merchant cargo ships 2003. https://www.sirc.cf.ac.uk/Uploads/In\%20House/GLM\%20for\%20Seafarers.pdf

Ellis N, Sampson H, Acejo I, Tang L, Turgo N, Zhao Z. (2012) Seafarer accommodation on contemporary cargo ships. Cardiff University.

EMSA. (2020). Seafarer statistics in the EU - statistical review (2018 data STCW-IS). http://www.emsa. europa.eu/publications/item/3977-seafarer-statistics-in-the-eu-statistical-review-2018-data-stcw-is. html

Gekara VO (2010) The stamp of neoliberalism on the UK tonnage tax and the implications for British seafaring. Mar Policy 34(3):487-494

Glen D (2008) What do we know about the labour market for seafarers?: a view from the UK. Mar Policy 32(6):845-855

Hand M (2018) Yet another EMSA audit deadline looms over Filipino seafarers. Seatrade Maritime. https://www.seatrade-maritime.com/asia/yet-another-emsa-audit-deadline-looms-over-filipino-seafa rers

ILO. (2001). The impact on seafarers' living and working conditions of changes in the structure of the shipping industry. International Labour Organization.

Leggate H (2004) The future shortage of seafarers: will it become a reality? Marit Policy Manag 31(1):3-13

Leong P (2012) Understanding the seafarer global labour market in the context of a seafarer'shortage' [PhD Thesis]. Cardiff University.

Li KX, Wonham J (1999) Who mans the world fleet? A follow-up to the BIMCO/ISF manpower survey. Marit Policy Manag 26(3):295-303

Lu C-S, Weng H-K, Huang F, Leung L-H, Wang W-D (2018) Assessing the seafaring intention of maritime students in Hong Kong. Transp Res Part A Policy Pract 110:258-273. https://doi.org/10.1016/j. tra.2017.10.007

Manoj P (2018) Armed with data, India says its seafarers are favourites worldwide. The Hindu Business Line. https://www.thehindubusinessline.com/companies/armed-with-data-india-says-its-seafarersare-favourites-worldwide/article22870392.ece

Mendoza RU, Valenzuela S (2017) Growing the Philippine blue economy: policy challenges and opportunities. Social Science Research Network. https://papers.ssrn.com/abstract=3040436

Sampson H, Bloor M (2007) When Jack gets out of the box: the problems of regulating a global industry. Sociology 41(3):551-569

Sulpice G (2011) Study on EU seafarers employment. European Commission. 
Tang L, Llangco MOS, Zhao Z (2016) Transformations and continuities of issues related to Chinese participation in the global seafarers' labour market. Marit Policy Manag 43(3):344-355

Tang L, Zhang P (2021) Human resource management in shipping: issues, challenges, and solutions. Routledge

UNCTAD (2019) Review of maritime transport 2018. United Nations.

US Maritime Administration. (2006). A review of crewing practices in U.S. - foreign ocean cargo shipping. https://www.maritime.dot.gov/sites/marad.dot.gov/files/docs/resources/3751/crewingreportin ternetversioninword-update-janfinal.pdf

Wu B, Winchester N (2005) Crew study of seafarers: a methodological approach to the global labour market for seafarers. Mar Policy 29(4):323-330

Publisher's note Springer Nature remains neutral with regard to jurisdictional claims in published maps and institutional affiliations. 